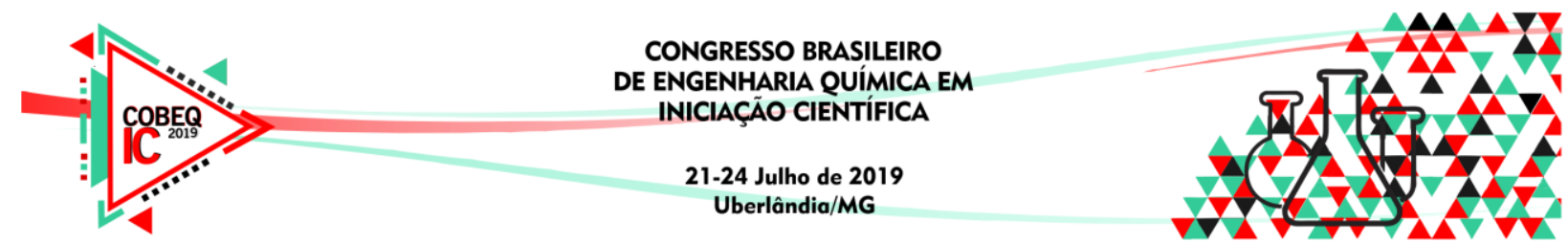

\title{
AVALIAÇÃO DA HIDRÓlISE ÁCIDA DO BAGAÇO DE ABACAXI PARA LIBERAÇÃO DE AÇUCARES FERMENTECÍVEIS
}

\author{
J. V. O. GOMES ${ }^{1}$, L. T. M. $\operatorname{LEMOS}^{2}$, L. L. MEDEIROS ${ }^{2}$, W. A. $\operatorname{COSTA}^{1}$ e F. L. H. \\ SILVA $^{2}$ \\ ${ }^{1}$ Universidade Federal da Paraíba, Graduação de Engenharia Química \\ ${ }^{2}$ Universidade Federal da Paraíba, Pós-graduação em Ciência e Tecnologia de
} Alimentos

E-mail para contato: joaovictorog@hotmail.com

\begin{abstract}
RESUMO - O abacaxi é um fruto muito consumido no Brasil. A cadeia produtiva gera grande acúmulo de resíduos, que pode causar danos ao meio ambiente. O bagaço do abacaxi apresenta potencial para obtenção de produtos de valor agregado, pois sua composição apresenta hemicelulose, componente da parede celular vegetal composta principalmente por xilose e arabinose. A hidrólise ácida possibilita a obtenção de açúcares fermentescíveis como substrato para leveduras na produção de xilitol e arabitol. Com isso, a pesquisa teve como objetivo avaliar a hidrólise ácida do bagaço de abacaxi para aplicação em produção biotecnológica de produtos de alto valor. As composições do bagaço do abacaxi antes e após a hidrólise foram, respectivamente, 13,08\% e 12,20\% de hemicelulose. A análise feita em HPLC constatou que a soma dos teores de xilose, arabinose e frutose foi de 32,30 g. $\mathrm{L}^{-1}$. Os resultados obtidos no presente estudo possibilitaram reavaliar a utilização de partes da matéria-prima, pois o resíduo de abacaxi obtido pelo processamento da polpa e da casca prensada resultou em teor de hemicelulose consideravelmente reduzido, assim como os valores de pentoses no licor.
\end{abstract}

\section{INTRODUÇÃO}

O desperdício de alimentos é um dos maiores problemas enfrentados mundialmente. Nosso hábito alimentar gera grande acúmulo de resíduos. Talos, cascas de frutas e folhas são jogados no lixo, mesmo contendo tantos nutrientes. No mesmo aspecto, a indústria de alimentos produz grande volume de resíduos, provenientes principalmente do beneficiamento de vegetais. A cadeia produtiva da maioria dos frutos consumidos no Brasil não tem planejamento para o reaproveitamento do material descartado pela linha de produção (GONDIM et al., 2005).

O acúmulo do resíduo vegetal no meio ambiente causa danos ecológicos irreparáveis, além de ser uma perda de ganhos financeiros para indústria. A comunidade científica tem buscado soluções para o acúmulo desse material. Diversas pesquisas têm estudado a produção biotecnológica de biocombustíveis renováveis, edulcorantes e fármacos (SEABRA et al., 2010). 


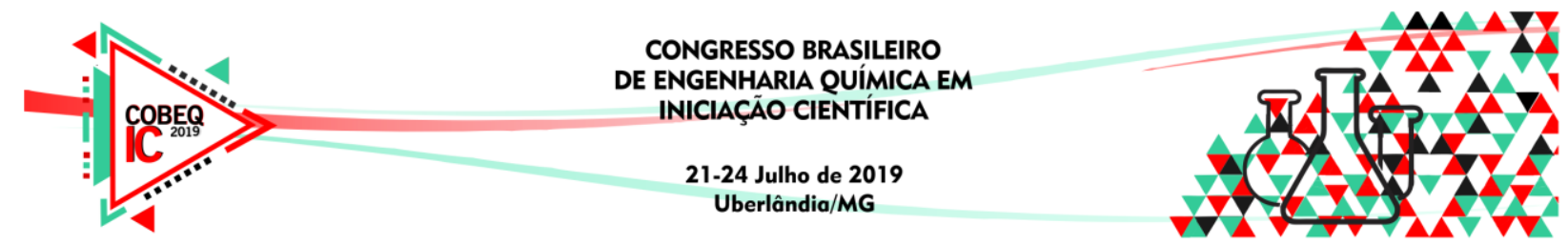

Dentre os tantos frutos cultivados no Brasil, o abacaxi (Ananas comosus L. Merril) é uma planta de clima tropical e um dos frutos mais consumidos no mundo. O Nordeste brasileiro concentra a parte majoritária de área plantada do abacaxi no país. Segundo o Instituto Brasileiro de Geografia e Estatística no ano de 2017, o estado da Paraíba foi o maior produtor de abacaxi. Essa mesma unidade federativa produziu 363.330 toneladas de abacaxi naquele ano, isso representa $61,01 \%$ da produção total do Nordeste e $24,18 \%$ da produção total do Brasil (IBGE, 2017).

A casca do abacaxi apresenta alto percentual de hemicelulose $(40,65 \%)$, que é basicamente formado de açúcares fermentescíveis. O aproveitamento dos açúcares presentes na porção hemicelulósica dos resíduos industriais depende da quebra dessa matriz, que pode se dar com ação ácida, básica ou enzimática. A hidrólise ácida se destaca pela sua eficiência e pelo baixo custo no processo. Os açúcares mais importantes provenientes dessa parte são: glicose, xilose e arabinose (LOUSADA JÚNIOR et al., 2006).

Alguns microrganismos utilizam esses açucares como substrato para a geração de produtos característicos do seu metabolismo. As leveduras são amplamente utilizadas para a obtenção de xilitol e arabitol através da fermentação de açúcares presentes em diversos hidrolisados (PRATTER et al., 2015).

A hidrólise ácida tem como intuito reduzir a proteção que a hemicelulose e a lignina conferem à celulose. A hidrólise ácida utilizando ácido sulfúrico $\left(\mathrm{H}_{2} \mathrm{SO}_{4}\right)$ na concentração $\left(1 \%\right.$ - 10\%) e temperatura na faixa de $100{ }^{\circ} \mathrm{C}$ a $160^{\circ} \mathrm{C}$ é um dos métodos mais utilizados, por resultar em altos rendimentos de solubilização de xilose. Alguns compostos provenientes do aquecimento de pentoses e hexoses podem gerar a formação de ácido acético, furfural e o hidroximetilfurfural. Esses compostos, quando presentes no hidrolisado, agem como inibidores do metabolismo microbiano sendo necessário uma posterior destoxificação do meio (ALVES et al., 2002; MUSSATO, ROBERTO, 2002).

A literatura relata a utilização de diversos resíduos para a produção biotecnológica de produtos de valor agregado. O bagaço do abacaxi é uma matéria prima potencial para bioprodução. Diante disso, o objetivo do trabalho foi avaliar a hidrólise do bagaço do abacaxi para obtenção de açúcares fermentescíveis, visando a produção biotecnológica de edulcorantes (xilitol e arabitol).

\section{METODOLOGIA}

\subsection{Matéria-prima}

O resíduo do processamento de abacaxi utilizado na pesquisa foi coletado na indústria INTRAFRUT - INDÚSTRIA TRANSFORMADORA DE FRUTAS S.A., localizada na cidade de João Pessoa-PB. O resíduo coletado era composto da casca do fruto mais a polpa prensada, sendo este o material de descarte da linha de produção da indústria citada. $\mathrm{O}$ material foi previamente lavado e seco $\left(65^{\circ} \mathrm{C}\right.$ até peso constante) antes de ser submetido ao processo de hidrólise. 


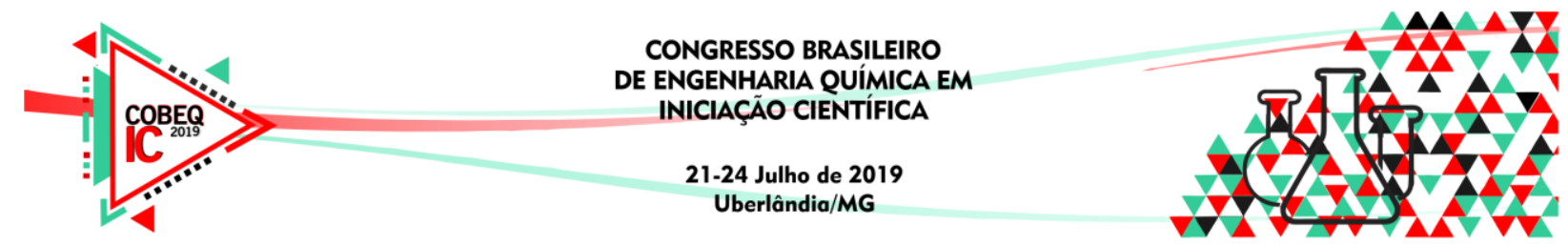

\subsection{Hidrólise ácida do bagaço de abacaxi}

A hidrólise ácida do bagaço de abacaxi foi realizada utilizando uma solução de $\mathrm{H}_{2} \mathrm{SO}_{4}$ na concentração de $1 \%$ (v/v), com proporção de 1:6 (gramas de bagaço: mililitros de solução ácida), em autoclave vertical (Phoenix Luferco: modelo AV - 50) a $105^{\circ} \mathrm{C}-1 \mathrm{~atm}$, com um tempo de residência de $40 \mathrm{~min}$. Após esse período, o material foi filtrado, sendo a parte líquida da hidrólise do abacaxi direcionado para quantificação dos açúcares e o material sólido para análise termogravimétrica após a hidrólise.

\subsection{Análise termogravimétrica (TGA)}

As análises foram realizadas no equipamento SEIKO (modelo TGA 50), localizado no Laboratório de Carvão Ativado, da Universidade Federal da Paraíba. Foram utilizados $10 \mathrm{mg}$, de amostra. A razão de aquecimento foi de $10^{\circ} \mathrm{C} / \mathrm{min}$, com intervalo de temperatura partindo da temperatura ambiente (aproximadamente $28^{\circ} \mathrm{C}$ ) até $900{ }^{\circ} \mathrm{C}$, sob um fluxo de nitrogênio de $25 \mathrm{~mL} / \mathrm{min}$.

\subsection{Cromatografia líquida de alta eficiência (HPLC)}

A determinação dos teores de açúcares (xilose e arabinose) no hidrolisado foi realizada em cromatógrafo HPLC (High Performance Liquid Chromatography) da marca VARIAN. O equipamento acoplado a um detector de índice de refração (Varian 356 - LC) e uma coluna Hi-Plex Ca (300mm x $7.7 \mathrm{~mm})$.

As amostras foram filtradas em filtro "Sep-Pack" C18 (Millipore), membrana de acetato celulose do tipo CHROMAFIL com poros de 0,45 $\mu \mathrm{m}$ (Waters associates - Millipore), injeção de $20 \mu \mathrm{L}$, numa fase móvel de água ultrapura, sob fluxo de $0,6 \mathrm{~mL} / \mathrm{min}$, temperatura do forno foi de $85^{\circ} \mathrm{C}$, com tempo de análise de $30 \mathrm{~min}$.

\section{RESULTADOS E DISCUSSÃO}

Diante dos resultados obtidos (Tabela 1) através da análise termogravimétrica foi possível obter as porcentagens de umidade, hemicelulose, celulose, lignina e outros constituintes sólidos. Uma das justificativas para os teores de hemicelulose e celulose exibidos na Tabela 1 e Figura 1 do presente estudo, abaixo do esperado, pode estar no fato de que durante o trabalho foram utilizadas apenas as partes da casca e da polpa prensado do abacaxi, pois de acordo com KASSIM et al. (2019) as coroas de abacaxi possuem teor de hemicelulose $(34,65 \%)$, celulose $(25,76 \%)$ e lignina $(20,33 \%)$, valores acima do encontrado nesse estudo. SILVA (2011) utilizou durante seu estudo a polpa prensada e coroa do abacaxi, afirmando que a junção dessas duas partes forma resíduo promissor para obtenção de açúcares fermentescíveis. 


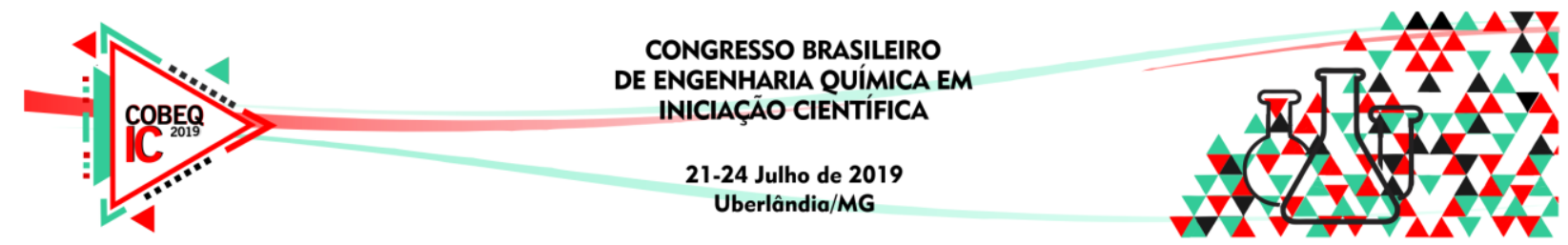

Tabela 1 - Análise termogravimétrica de resíduo do abacaxi antes e após o processo de hidrólise

\begin{tabular}{cccc}
\hline Componentes do resíduo & Faixa de temperatura & $\begin{array}{c}\text { Composição do } \\
\text { resíduo }(\%)\end{array}$ & $\begin{array}{c}\text { Composição do } \\
\text { resíduo } \\
\text { pós-hidrólise } \\
(\boldsymbol{\%})\end{array}$ \\
\hline Água livre & $25-50$ & 2,58 & 2,28 \\
Água ligada & $50-125$ & 6,58 & 1,94 \\
Umidade & $25-125$ & 9,16 & 4,22 \\
Constituintes voláteis & $125-199$ & 9,36 & 24,55 \\
Lignina & $200-550$ & 24,58 & 33,13 \\
Hemicelulose & $250-300$ & 13,08 & 12,20 \\
Celulose & $300-365$ & 14,58 & 14,73 \\
Outros constituintes & $550-850$ & 14,58 & -- \\
Cinzas & -- & 8,25 & 2,00 \\
Total & & $\mathbf{9 3 , 3 2}$ & $\mathbf{9 0 , 8 3}$ \\
\hline
\end{tabular}

As Figuras 1 e 2 mostram os estágios de perda de massa representando a degradação de cada componente das amostras, antes e após o tratamento ácido, a medida que a temperatura vai aumentando. O primeiro estágio representa a vaporização da água (livre e ligada) com temperatura em torno de $105{ }^{\circ} \mathrm{C}$, acima desse valor observa-se a volatilização de alguns constituintes da amostra. Segundo RAMBO et al. (2015) a hemicelulose e a celulose começam a se decompor na faixa de temperatura de $250{ }^{\circ} \mathrm{C}$ à $400{ }^{\circ} \mathrm{C}$, acima de $400{ }^{\circ} \mathrm{C}$ a lignina começa a se decompor lentamente e ao final do processo ocorre a formação de cinzas. As faixas de temperatura foram coerentes com as esperadas, porém os teores de hemicelulose e celulose tanto do bagaço do abacaxi antes da hidrólise como do bagaço pós-hidrólise ficaram abaixo dos descritos na literatura.

Figura 1 - Análise termogravimétrica (DTG) do resíduo do abacaxi

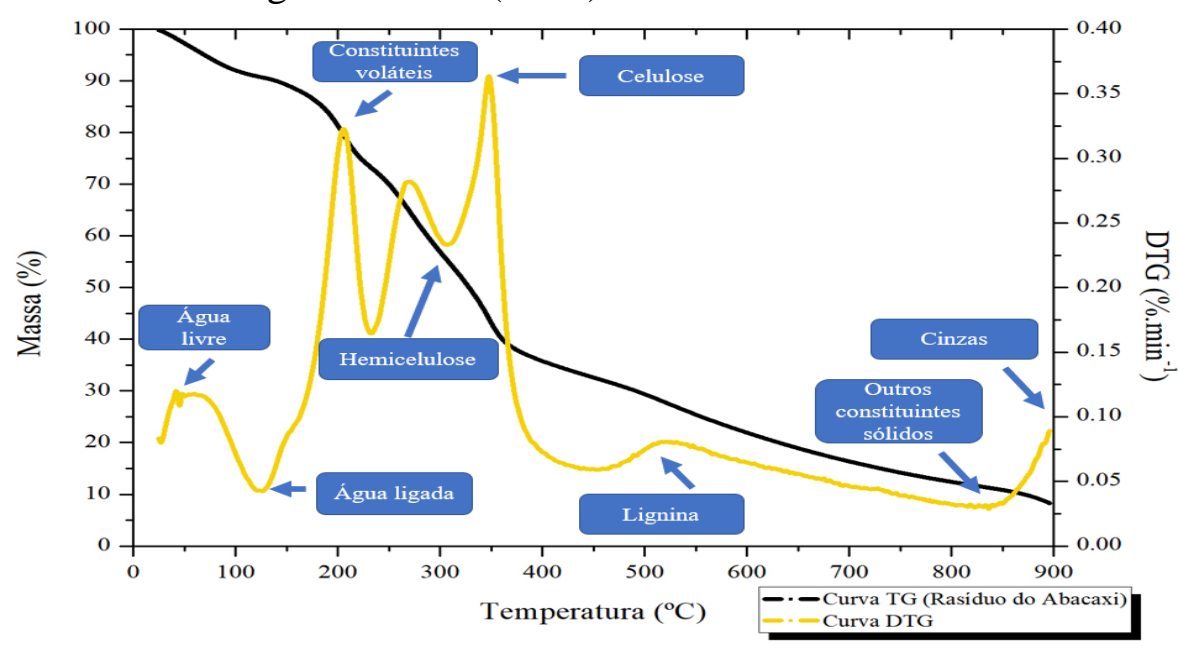




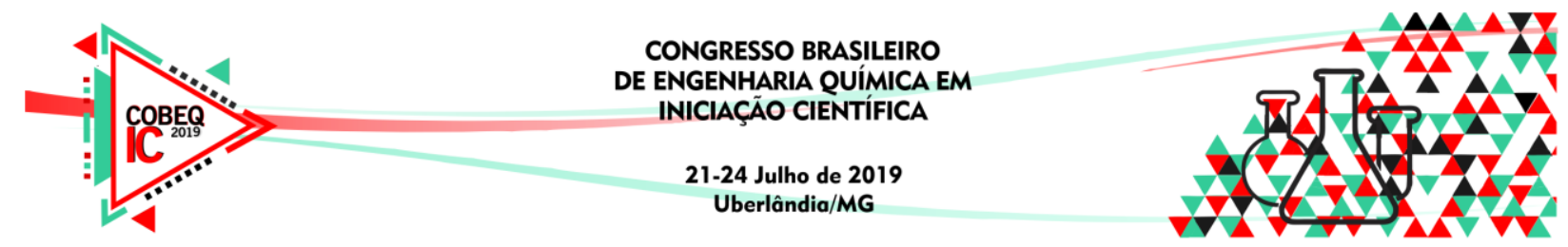

Figura 2 - Análise termogravimétrica (DTG) do resíduo do abacaxi pós-hidrólise

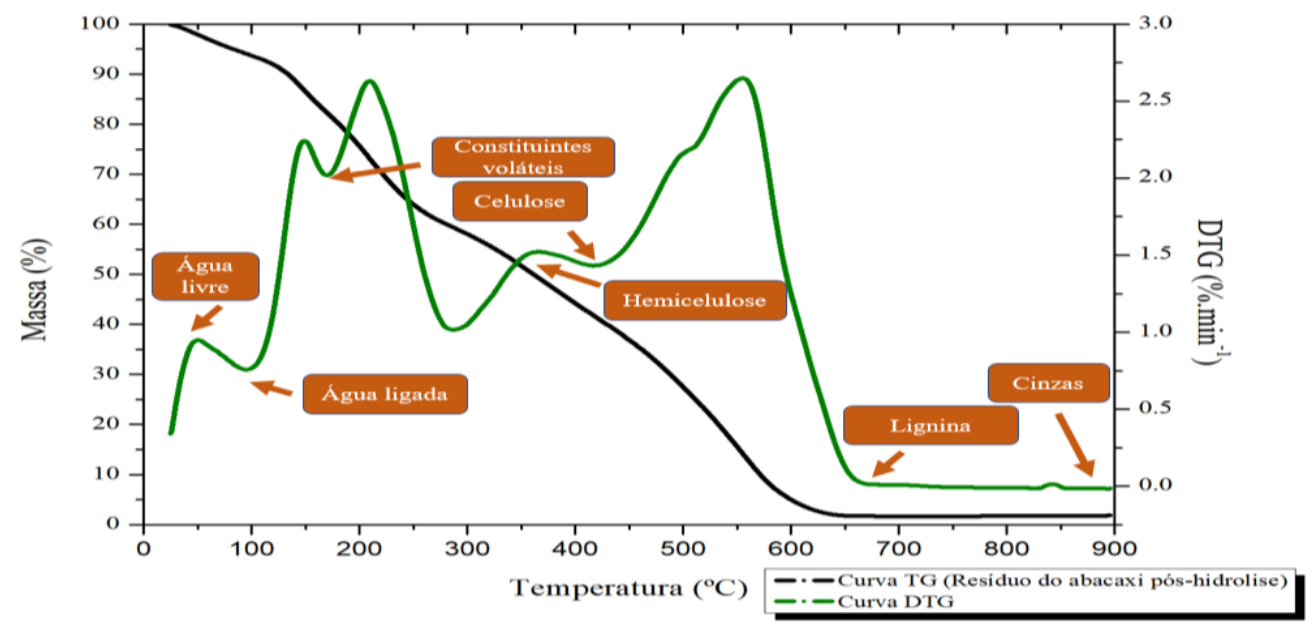

Comparando as Figuras 1 e 2, observa-se que a composição de hemicelulose foi pouco reduzida $(0,88 \%)$ no pós-tratamento ácido, possuindo $13,08 \%$ para $12,20 \%$, antes e após o tratamento, respectivamente. Verifica-se que o tratamento ácido não foi eficiente na desconstrução do material lignocelulósico, ou seja, separação da celulose, hemicelulose e lignina. Sendo assim, será necessário posterior estudo da hidrólise ácida utilizando parâmetros mais drásticos (maior concentração de ácido, maior temperatura e maior tempo de reação) para observar o comportamento do resíduo.

Tabela 2 - Composição de xilose e arabinose do hidrolisado do bagaço de abacaxi

\begin{tabular}{cc}
\hline Composição & Teor $\left(\mathbf{g} \cdot \mathbf{L}^{-\mathbf{1}}\right)$ \\
\hline Glicose & $25,58 \pm 0,54$ \\
Xilose & $5,25 \pm 0,57$ \\
Arabinose + Frutose & $27,05 \pm 0,43$
\end{tabular}

Pelos dados da Tabela 2, pode-se constatar pela análise de HPLC que o teor de hemicelulose no licor hidrolisado é baixo (soma de xilose, arabinose e frutose foi de 32,30 g. $\left.\mathrm{L}^{-1}\right)$. Verifica-se que há uma quantidade de monossacarídeos como glicose e frutose, que estão principalmente presentes na polpa e no talo do abacaxi, mostrando que a parte lignocelulósica (casca) estava em quantidade reduzida no bagaço utilizado nesse estudo.

\section{CONCLUSÕES}

O bagaço de abacaxi, formado pela casca e a polpa prensada apresentou baixo percentual de hemicelulose. Por consequência, o processo de hidrólise ácida apresentou teores reduzidos de xilose e arabinose. 


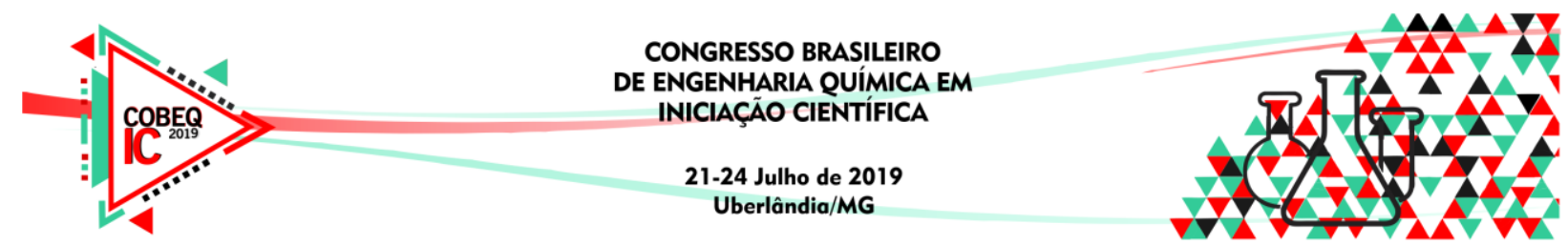

\section{REFERÊNCIAS}

ALVES, L. A.; VITOLO, M.; FELIPE, M. G. A.; SILVA, J. B. A. Xylose reductase and xylitol dehydrogenase activities of Candida guilliermondii as a function of different treatments of sugarcane bagasse hemicellulosic hydrolysate employing experimental design. Applied Biochemistry and Biothecnology, v. 98, p. 403-413, 2002.

GONDIM, J. A. M.; MOURA, M. F. V.; DANTAS, A. S.; MEDEIROS, R. L. S. \& SANTOS; K. M. 2005. Composição centesimal e de minerais em cascas de frutas. Ciência e Tecnologia de Alimentos, v. 25, no. 4, p. 825-827. Campinas, 2005.

IBGE - INSTITUTO BRASILEIRO DE GEOGRAFIA E ESTATÍSTICA. SIDRA - Sistema IBGE de Recuperação Automática, 2017. Disponível na internet via https://sidra.ibge.gov.br/tabela/1612. Arquivo consultado em 23 de março de 2019.

KASSIM, N. A.; Mohamed, A. Z.; Zainudin, E. S.; Zakaria, S.; Azman, S. K. Z.; Abdullah, H. H. Isolation and characterization of macerated cellulose from pineapple leaf. BioResources, v. 14, n. 1, p. 1185-1197. 2019.

LOUSADA, J. J. E.; COSTA, J. M. C.; NEIVA, J. N. M.; RODRIGUEZ, N. M. Caracterização físico-química de subprodutos obtidos do processamento de frutas tropicais visando seu aproveitamento na alimentação animal. Revista Ciência Agronômica, v. 37, n. 1, p. 70-76. Ceará, 2006.

MUSSATO, I. S.; ROBERTO, I. C.; Produção biotecnológica de xilitol a partir da palha de arroz. Biotecnologia Ciência e Desenvolvimento, n. 28, p. 34-39. Brasília, 2002.

PRATTER, S. M.; EIXELSBERGER, T.; NIDETZKY, B. Systematic strain construction and process development: Xylitol production by Saccharomyces cerevisiae expressing Candida tenuis xylose reductase in wild-type or mutant form. Bioresource Technology, v. 198, p. 732-738, 2015.

RAMBO, M. K. D.; RAMBO, M. C. D.; ALMEIDA, K. J. C. R.; ALEXANDRE, G. P. Estudo de análise termogravimétrica de diferentes biomassas lignocelulósicas utilizando a análise por componentes principais. Ciência e Natura, v. 37, n. 3, p. 862-868. Santa Maria, 2015.

SEABRA, J. E. A.; MACEDO, I. C.; LEAL. M. R. L. V. Emissões de gases de efeito estufa relacionados ao etanol de cana-de-açúcar. In Bioetanol de cana-de-açúcar: P\&D para produtividade e sustentabilidade. São Paulo: Blucher, 2010.

SILVA, O. O. Aproveitamento do bagaço de abacaxi (Ananas comunos L. Merril) para a produção biotecnológica de xilitol. 2011. 105-117 f. Tese (Doutorado) - Programa de PósGraduação em Ciência e Tecnologia de Alimentos, Universidade Federal de Viçosa, Minas Gerais, 2011.

SUN, Y.; CHENG, J. Hydrolysis of lignocellulosic materials for ethanol production: a review. Bioresource Technology, v. 83, p. 1-11, 2002. 